
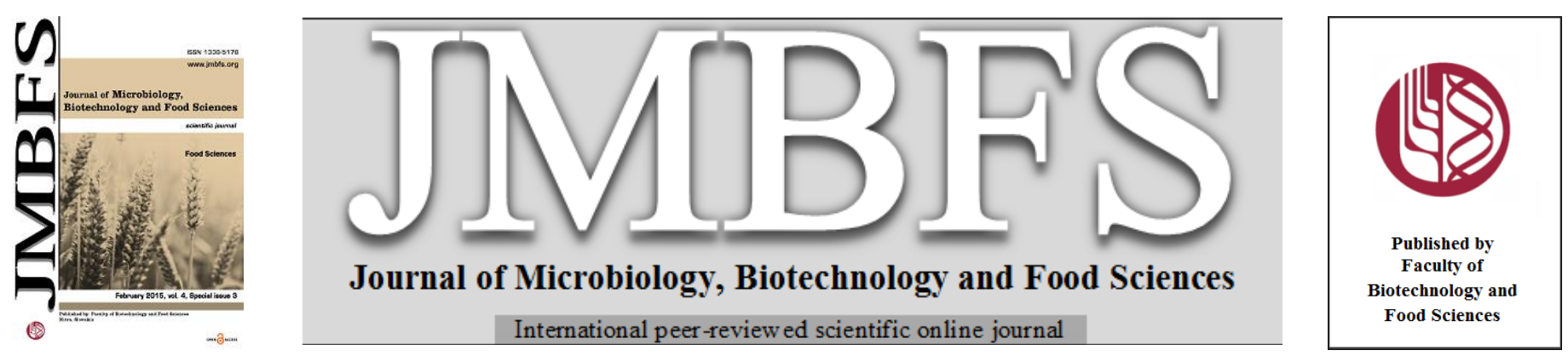

\title{
UNCOMMON SENSORY METHODOLOGIES
}

\section{Vladimír Vietoris*, Hana Balková, Peter Czako, Tatiana Bojňanská}

Address(es): Ing. Vladimír Vietoris, PhD.

${ }^{I}$ Slovak University of Agriculture, Faculty of Biotechnology and Food Sciences, Department of Plant Products Storage and Processing, Tr. A. Hlinku 2, 94976

Nitra, Slovakia, phone number: +421376414793.

*Corresponding author: vladimir.vietoris@ uniag.sk

doi: $10.15414 /$ jmbfs.2015.4.special3.170-172

\section{ART ICLE INFO}

Received 30.11. 2014

Revised 5. 12. 2014

Accepted 6. 12. 2014

Published 2.2.2015

\section{Review}

OPEN $\bigodot_{\text {ACCESS }}$

\section{ABSTRACT}

Sensory science is the young but the rapidly developing field of the food industry. Actually, the great emphasis is given to the production of rapid techniques of dat a collection, the difference between consumers and trained panel is obscured and the role of sensory methodologists is to prepare the ways for evaluation, by which a lay panel (consumers) can achieve identical results as a trained panel. Currently, there are several conventional methods of sensory evaluation of food (ISO standards), but more sensory labo ratories are developing methodologies that are not strict enough in the selection of evaluators, their mechanism is easily understandable and the results are easily interpretable. This paper deals with mapping of marginal methods used in sensory evaluation of food (new types of profiles, CATA, TDS, napping).

Keywords: FCP, Flash profile, CAT A, TDS

\section{INTRODUCTION}

Sensory methodologies are still growing fast and hard. Many of these methods are simple and easy to apply, whereas others are more complex and require training and experience. These methods and their practical application must be independent, technically competent and as objective as possible. So, selection of the appropriate sensory method and testing conditions provide powerful results. Here is a list of some nowadays methodologies.

\section{Free-choice profile (FCP)}

New types of profiles aim at providing a quick sensory positioning of a set of products and thus by pass the time-consuming steps of attribute and scaling alignment of classical methods. These new methods build on the idea of free choice profiling that allows assessors to use their own attributes (Abdi and Valentin, 2007).

Free-choice profile (FCP) is a method of sensory analy sis that can be carried out by untrained panel. The assessors need only to be able to use a scale and consuming the product under ev aluation (Aparicio et al., 2007). It is a relatively easy, quick and inexpensive sensory method that allows an insight into the perception of products from consumers view (Frances and Piggott, 2003). FCP is a sensory methodology that differs from other descriptive methods because it is not necessary to use a common vocabulary of attributes to describe the samples, nor are the panelists expected to agree on their interpretation of the terms used (Williams and Langron, 1984). This is based on the assumption that assessors do not differ in their perceptions, but merely in the way in which they describe them. Free-choice profile is similar to conventional profiling in that assessors should be able to detect differences between the samples, verbally describe the perceived attributes and quantify them (Oreskovich et al., 1991). In this methodology, assessors not only set their own descriptors, but also measure their intensity and acceptability. Before the evaluation, it is necessary that the assessors were given adequate instructions and several descriptors on consideration (appearance, flavor, texture, etc.)(González-Vinas et al., 2001). The FCP method can yield important insights into consumer differentiation of products and establish relationships between sensory characteristics and consumer preferences (Jack and Piggott, 1992). Regarding the number of at tributes generated, this is limited only by the perceptual and descriptive skills of the consumer (Oreskovich et al.,1991) and according to Deliza et al. (2005), terms used by untrained assessors may vary, based on their individual experience and familiarity with the product. This method allows consumers to use any number of words in the description and evaluation of the intensity of selected attributes, resulting in a more effective overview of consumer perception and acceptance of products (González-Viñas et al.,2001; Delizia et al., 2005). The data are analyzed by sophisticated statistical methodologies like Generalized Procrustean Analysis (GPA) or ST ATIS (Aparicio et al., 2007).

Generalized Procrustes Analysis (GPA) is a useful tool for sensory professionals to analyze sensory data, especially those from free choice profiling, because it can accommodate different numbers and types of attributes among assessors. Moreover, GPA can be used for visually describing of different effects, such as product differences, assessor agreement and repeatability (Xiong et al., 2008). It is a multivariate exploratory technique that involves transformations (i.e., translation, rotation, reflection, isotropic rescaling) of individual data matrices to provide optimal comparability. The average of the individual matrices is called the consensus matrix. The individual and consensus matrices are typically submitted to Principal Components Analysis (PCA) and projected onto a lower dimensional space that provides a vantage point to compare individual data and to visualize the consensus (Dijksterhuis and Heiser, 1995). The whole procedure of data translation is digestedly illustrated in the figure 1 .

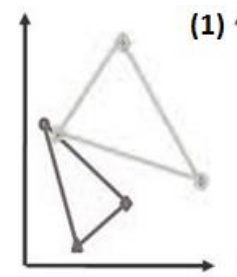

(1)

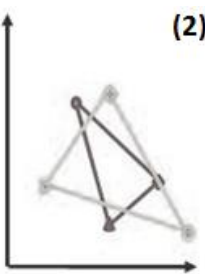

(2)

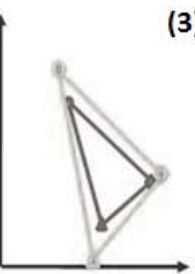

(4)

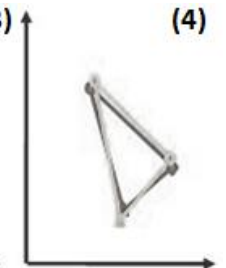

Figure 1 The individual phases of Generalized Procrustes Analysis (GPA). Translation (1), rotation (2), reflection (3), isotropic rescaling (4) (Meullenet et al., 2007)

\section{Flash profile (FP)}

Flash profile is a quick sensory profiling technique designed to meet industrial needs. This method, initially developed (Sieffermann, 2000) is based on the combination of free choice profiling and a comparative evaluation of the whole product set (Delarue and Sieffermann, 2004). The advantage of Flash profile is that the paneldoes not have to be trained in the long term and methodology of evaluation can manage well informed consumer. The objective of this technique is achieved the rapid sensory arrangement of the whole product set and thus replace the time-consuming procedures involved in conventional methods (Abdi 
and Valentin, 2007). The assessors select their own attributes and then rank order the products from least to most on each of their chosen descriptors. They are allowed to generate as many at tributes as they want, but are asked to focus on descriptive terms and to avoid hedonic terms. Assessors can re-taste the products as often as they want (Valentin et al., 2012). The way of evaluation transcription is illustrated in the figure 2 . That is, the assessor ranks the products on abscissae of attributes in order and subsequently the transcription is converted into order.

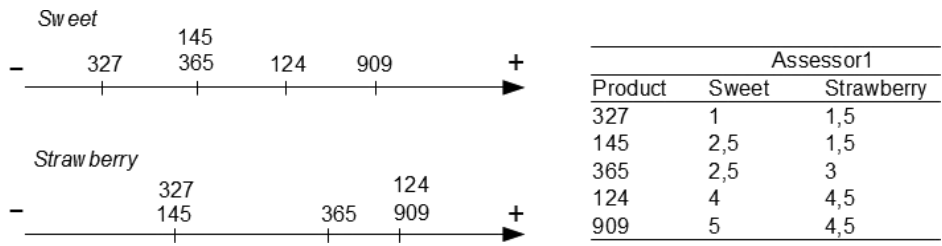

Figure 2 The form of transcription and conversion of Flash profile data (Valentin et al., 2012)

Ranking lists of all assessors are processed by GPA and are mostly presented by two-dimensional graph similar to the map of the principal components. After GPA it can be possible to make cluster analysis on descriptive terms, which may facilit ate their easier interpretation (Tarea et al., 2007). Flash profile became very popular in laboratory sensory analysis and its further modifications as ranking descriptive analysis (RDA) are rising. This method was designed by Bragato Richter (2010). Methodological it is allied to "classical profile" and presents some of compromise between the descriptive classic profile and free choice profiling because it uses fixed form of attributes and ordinal scales.

\section{Check-all-that-apply (CATA)}

CAT A method is based on verbal interpretation and free choice profiling. It provides information about the attributes that are detectable according to consumers and relate with overall popularity and acceptability of products (Stone and Sidel, 2007). This technique consists of a list of attributes (words or phrases) from which assessors select all the attributes appropriate and typical for a product. Assessors evaluate each product and check in the list the attributes that best describe the product. They can check as many attributes as they want and can take as much time as needed (Valentin et al.,2012). CATA method is easier, less time consuming and more natural for assessors in compare with scaling (Adams et al.,2007; Ares et al.,2010b). Driesener and Romaniuk (2006) used this methodology for the survey of consumer perception of different brands of products. According to these authors CAT A method gives identical results compared with othertime-consuming sensory techniques. This method can be done in several ways: consumers can select words to describe the product during the evaluation, the entry form can provide a trained panel (Dooley et al., 2010), or dates for evaluation may be intended in the consumer group interviews (focus group), respectively alternative can be determined from the questionnaires with open questions (Ares et al., 2010a). The result of the data processing for this technique is matrix of frequencies and subsequent post-production of results by technique Correspondence analysis. Specialized software generates sensory map of similarities. Some authors suggest a more sophisticated approach using Mult ifact or analysis respectively Multiple Correspondence analysis (Ares $\boldsymbol{e t}$ al., 2011a,b). The result of data processing for this technique is a map of the similarity of products flashback in two-dimensional space as illustrated in the figure 3 .

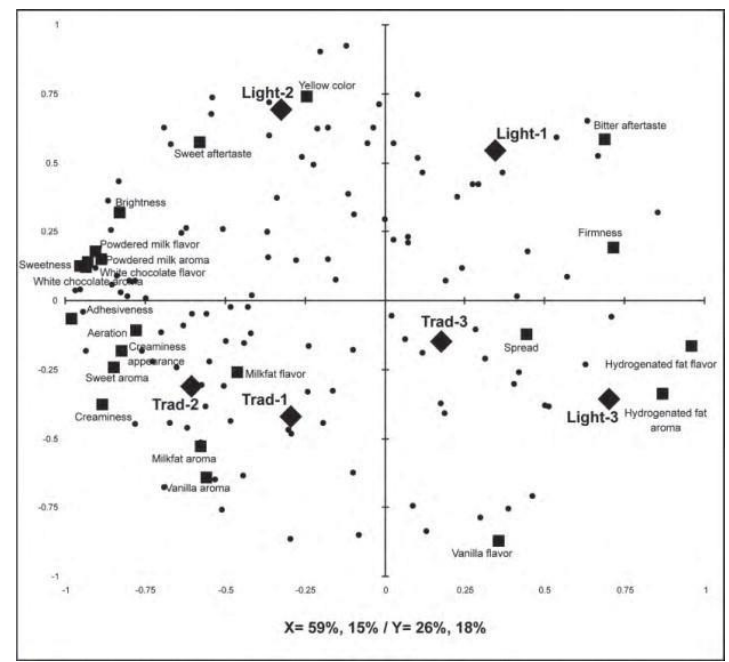

Figure 3 Example of the output at Check-all-that-apply (CATA) method (Cadena et al., 2012)

\section{Temporal dominance of sensations (TDS)}

Temporal dominance of sensations (TDS) is a recent descriptive sensory method consisting in assessing repeatedly, until the sensations end, which sensation is dominant and in scoring its intensity. Compared to time-intensity, this technique considers the multidimensionality of the perceptual space over time. TDS provided reliable information close to conventional sensory profiling. In addition, TDS method provided information on the dynamic of perception after consumption of product that was not available using a conventional profiling method and that may be critical for the understanding of complex perceptions such as refreshing (Labbe et al., 2009). The method aims at studying these quence of the most dominant sensations during a certain time period like the mastication or the after taste period. Investigating the quality of the panel and hence of the data is essential to judge on the reliability of the results and their interpretation. In contrast to sensory profiling, TDS includes a temporal dimension (Meyners, 2011). The TDS curves computation is explained in the figure 4 .

This method is mainly used for a description of the characteristics of each single product over time (Meyners and Pineau, 2010). The method consists in presenting the whole set of attributes to the panelist on the computer screen with corresponding unstructured linear scales. The assessor after drinking or swallowing samples presses the start butt on and selects a dominant attribute on a computerscreen, while its intensity is measured, usually on the 10 point scale. After the end of evaluation, it is necessary to process the results (Le Reverend $\boldsymbol{e t}$ al., 2008).

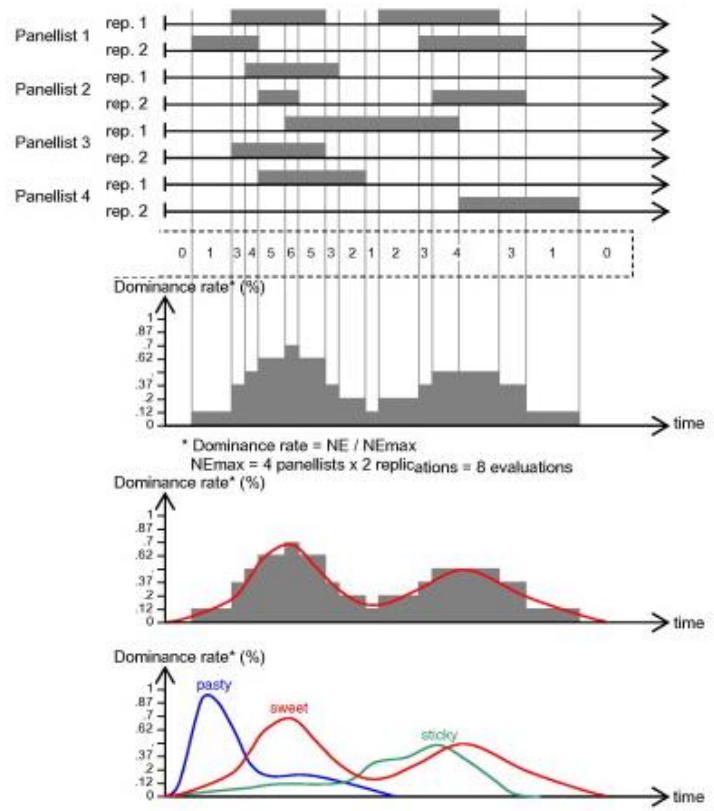

Figure 4 Methodology to compute TDS curves (Pineau et al., 2012)

Temporal dominance of sensations is from time and financial point of view more effective than one monitoring by Time intensity method because of several attributes evaluation in a single measurement. TDS is simple and easily enforceable and requires only minimal training of assessors. This technique requires specialized software of collecting data (Labbe et al., 2009).

\section{CONCLUSION}

To sum up, sensory analysis of food is perspective science that more and more clearly connects marketing practices and analysis of consumer behavior. Currently, there are a number of new approaches based on simplicity, clarity and due to sensometry processes the elimination of extreme values and reproducibility of the results. Recently, a less known laboratory methods come to the foreground by which it can be accurately evaluated and determined the quality of the products. These methods provide information about specific differences between products, the consumers' desire for new product development in the food industry, help product developers to identify potential risks and have an important position in a survey of demand. Their advantages are mainly the rapidity of applications, simplicity of methodology and effectiveness at work with a lay panel. 


\section{AC KNO W LEDGEMENTS}

This work was supported by the Slovak Research and Development Agency under the contract No. APVV-0629-12.

\section{REFERENCES}

ABDI, H., VALENT IN, D. 2007. Some new and easy ways to describe, compare, and evaluate products and assessors. In D. VALENTIN, D.Z. NGUYEN, L. PELLETIER. New trends in sensory evaluation of food and non-food products, 5-18. Vietnam: Vietnam National University-Ho chi Minh City Publishing House.

ADAMS, J., WILLIAMS, A., LANCASTER, B., FOLEY, M. 2007. Advantages and uses of check-all-that-apply response compared to traditional scaling of attributes for salty snacks (Proceding of the work of 7th Pangborn Sensory Science Symposium), Minneapolis.412-418.

APARICIO, J. P., MEDINA, M. A. T., ROSALES, V. L. 2007. Descriptive sensory analysis in different classes of orange juice by a robust free-choice profile method. Analytica Chimica Acta, 595(1-2), 238 247.http://dx.doi.org/10.1016/j.aca.2007.02.054

ARES, G., BARREIRO, C., DELIZA, R., GIMÉNEZ, A., GÁMBARO, A. 2010a. Application of a check-all-that-apply question to the development of chocolate milk desserts. Journal of Sensory Studies, 25(1), 6786.http://dx.doi.org/10.1111/j.1745-459x.2010.00290.x

ARES, G., DELIZA, R., BARREIRO, C., GIMÉNEZ, A., GÁMBARO, A. 2010b. Comparison of two sensory profiling techniques based on consumer perception. Food Quality and Preference, 21(4), 417426.http://dx.doi.org/10.1016/j.foodqual.2009.10.006

ARES, G., VARELA, P., RADO, G., GIMÉNEZ, A. 2011 a. Identifying ideal products using three different consumer profiling methodologies. Comparison with external preference mapping. Food Quality and Preference, 22(6), 581591.http://dx.doi.org/10.1016/j.foodqual.2011.04.004

ARES, G., VARELA, P., RADO, G., GIME'NEZ, A. 2011 b. Are consumer profiling techniques equivalent for some product categories? The case of orangeflavoured powdered drinks. International Journal of Food Science and Technology, 46(8), 1600-1608. http://dx.doi.org/10.1111/j.13652621.2011.02657.x

CADENA, R.S., CRUZ, A.G., FARIA, J.A.F., BOLINI, H.M.A. 2012. Reduced fat and sugar vanilla ice creams: Sensory profiling and external preference mapping. Journal of Dairy Science, 95(9), 4842-4850. http://dx.doi.org/10.3168/jds.2012-5526

DELARUE, J., SIEFFERMANN, J.M. 2004. Sensory mapping using Flash profile. Comparison with a conventional descriptive method for the evaluation of the flavour of fruit dairy products. Food Quality and Preference, 15(4), 383392.http://dx.doi.org/10.1016/s0950-3293(03)00085-5

DELIZA, R., MACFIE, H., HEDDERLEY, D. 2005. The consumer sensory perception of passion-fruit juice using free-choice profiling. Journal of Sensory Studies, 20(1), 17-27.http://dx.doi.org/10.1111/j.1745-459x.2005.050604.x DIJKST ERHUIS, G. B., HEISER, W. 1995. The role of permutation tests in exploratory multivariate data analysis. Food Quality and Preference, 6(4), 263 270.http://dx.doi.org/10.1016/0950-3293(95)00025-9

DOOLEY, L., LEE, Y.S., MEULLENET, J.F. 2010. The application of chec-allthat-apply (CATA) consumer profiling to preference mapping of vanilla ice cream and its comparasion to classical external preference map ping. Food Quality and Preference, 21(4), 394401.http://dx.doi.org/10.1016/j.foodqual.2009.10.002

DRIESENER, C., ROMANIUK, J. 2006. Comparing methods of brand image measurement. International Journal of Market Research, 48(6), 681-698.
FRANCES R. J., PIGGOTT, J.R. 2003. Free choice profiling in consumer research. Food Quality and Preference, 3(3), 129. 134.http://dx.doi.org/10.1016/0950-3293(91)90048-j

GONZÁLEZ-VIÑAS, M. A., GARRIDO, N., WIT TIG DE PENNA, E. 2001. Free choice profiling of Chilean goat cheese. Journal of Sensory Studies, 16(3), 239-248.http://dx.doi.org/10.1111/j.1745-459x.2001.tb00298.x

JACK, F. R., PIGGOTT, J. R. 1992. Free choice profiling in consumer research. Food Quality and Preference, 3(3), 129-134.http://dx.doi.org/10.1016/09503293(91)90048-j

LABBLE, D., SCHLCH, P., PINEAU, N., GILBERT, F., MART IN, N. 2009. Temporaldominance of sensations and sensory profiling: A comparative study. Food Quality and Preference, 20(3), 216221.http://dx.doi.org/10.1016/j.foodqual.2008.10.001

LE REVEREND, F.M., HIDRIO, C., FERNANDES, A., AUBRY, V. 2008 Comparasion between temporal dominance of sensation and time intensity results. Food Quality and Preference, 19(2), 174178.http://dx.doi.org/10.1016/j.foodqual.2007.06.012

MEULLENET, J.F., XIONG, R., FINDLAY, C. 2007. Multiv ariate and probabilistic analyses of sensory science problems. First edit. Iowa: Blackwell Publishing Professional, 256 p. ISBN 978-0-8138-0178-0.

MEYNERS, M., PINEAU, N. 2010. Statistical inference for temporal dominance of sensations data using randomization tests. Food quality and Preference, 21(7), 805-814.http://dx.doi.org/10.1016/j.foodqual.2010.04.004

MEYNERS, M. 2011. Panel and panelist agreement for product comparisons in st udies of temporal dominance of sensations. Food quality and Preference, 22(4), 365-370.http://dx.doi.org/10.1016/j.foodqual.2011.01.006

ORESKOVICH, D. C., KLEIN, B. P., SUTHERLAND, J. W. 1991. Procrustes analysis and its application to free choice and other sensory profiling. Sensory science theory and application in foods. 353-394.

PINEAU, N., SCHLICH, P., CORDELLE, S., MATHONNIČRE, C., ISSANCHOU, S., IMBERT, A., ROGEAUX, M., ETIÉVANT, P., KÖST ER, E. 2009. Temporal Dominance of Sensations: Construction of the TDS curves and comparison with time-intensity. Food Quality and Preference, 20(6), 450455.http://dx.doi.org/10.1016/j.foodqual.2009.04.005

SIEFFERMANN, J.M. 2000. Le profil flash - un outil rapide et innovant d'évaluation sensorielle 683 descriptive. AGORAL XIIèmes rencontres “'L'innovation: de l'idée au succès' 684 Montpellier, France, 335-340.

ST ONE, H., SIDEL, J. L. 2007. Sensory research and consumer-led food product development. In H. J. H. MacFie (Ed.), Consumer-led food product development. Cambridge, England: Woodhead Publishing Limited, 307320.http://dx.doi.org/10.1533/9781845693381.3.307

T AREA, S., CUVELIER, G., SIEFFERMANN, J.M. 2007. Sensory evaluation of the texture of 49 commercial apple and pear purees. Journal of Food Quality, 30(6), 1121-1131.http://dx.doi.org/10.1111/j.1745-4557.2007.00174.x

VALENT IN, D.,CHOLLET, S., LELIE` VRE, M., ABDI, H. 2012. Quick and dirty but still pretty good: a review of new descriptive methods in food science. International Journal of Food Science and Technology. 47(8), 15631578.http://dx.doi.org/10.1111/j.1365-2621.2012.03022.x

WILLIAMS, A., LANGRON, S.P.1984. The use of free choice profiling for the evaluation of commercial ports. Journal of Science and Food Agriculture, 35(5), 558-568.http://dx.doi.org/10.1002/jsfa.2740350513

XIONG, R., BLOT, K., MEULLENET, J.F., DESSIRIER, J.M. 2008 Permutation tests for Generalized Procrustes Analysis. Food Quality and $\begin{array}{llll}\text { Preference, } & 19(2), & 2008, & \text { p. }\end{array}$ 155.http://dx.doi.org/10.1016/j.foodqual.2007.03.003 